\title{
Metal-Containing Initiator Systems. XXX. Selective Initiation of Polymerization with Reduced Nickel/Organic Halides: Cationic Polymerization of Styrene and Isobutyl Vinyl Ether
}

\author{
Shuzo Aoki, Chiaki Shirafuji, and Takayuki Otsu \\ Department of Applied Chemistry, Faculty of Engineering, \\ Osaka City University, \\ Sumiyoshi-ku, Osaka, Japan. \\ (Received December 14, 1970)
}

\begin{abstract}
It was found that the binary system composed of reduced nickel and alkyl halides, such as tert-butyl chloride and carbon tetrachloride, initiates both radical and cationic polymerizations of vinyl monomers. From the effects of inhibitors the polymerization of styrene with this initiator was confirmed to proceed through both radical and cationic intermediates. Nickel halides produced by the reaction of the reduced nickel with the alkyl halides are proposed as the active species for the cationic initiation. Nickel sesquioxide reacted with tert-butyl chloride giving nickel chloride which was active for the initiation of the cationic polymerization of styrene and isobutyl vinyl ether. The binary system composed of nickel carbonyl and carbon tetrachloride, which is known as a radical initiator, also showed cationic activity in the polymerization of isobutyl vinyl ether. The activity of the reduced nickel as a catalyst in the FriedelCrafts reaction was also investigated. The condensation of benzyl chloride, giving polybenzyl, resulted from heating with the reduced nickel.

KEY WORDS Initiation/Cationic Polymerization/Styrene / Isobutyl Vinyl Ether/Alkyl Halide/Reduced Nickel/Nickel Oxide/Nickel Carbonyl/Polybenzyl/
\end{abstract}

It has been reported that the binary system composed of reduced nickel and organic halides initiated radical polymerization of vinyl monomers (eq 1 and 2 ). ${ }^{1-4}$

$$
\begin{aligned}
& \mathrm{Ni}+\mathrm{R}-\mathrm{X} \longrightarrow \mathrm{R} \cdot+1 / 2 \mathrm{Ni}^{++}+\mathrm{Cl}^{-} \\
& \mathrm{R} \cdot+\text { Monomer } \longrightarrow \mathrm{R}-\text { Monomer }
\end{aligned}
$$

Recently it has been found that some metal/organic halide systems also initiate cationic polymerization. The reduced nickel/chlorosilanes ${ }^{4}$ and tin/benzyl chloride ${ }^{5}$ initiated both the radical polymerization of methyl methacrylate (MMA) and the cationic polymerization of isobutyl vinyl ether (IBVE).

In this paper the initiating activity of the reduced nickel/alkyl halides $(\mathrm{Ni} / \mathrm{R}-\mathrm{X})$ for the cationic polymerization of styrene and IBVE was investigated in order to elucidate the intiation mechanism.

\section{RESULTS AND DISCUSSION}

Effect of Additives on Polymerization of Styrene with $\mathrm{Ni} / \mathrm{R}-\mathrm{X}$

The polymerization of styrene with Ni/R-X may give a mixture of radical and cationic polymers, if the initiator is active for both radical and cationic polymerizations.

In order to determine the polymerization mechanism with Ni/R-X styrene was polymerized in the presence of oxygen as a radical inhibitor and water as a cationic inhibitor. tert-Butyl chloride and carbon tetrachloride were used for the alkyl halide component of the initiator. The results are given in Table $\mathrm{I}$.

The initiator showed high activity in the absence of any inhibitor, though the molecular weight of the resulting polymers was very low.

Oxygen did not affect the polymerization, but a trace of water greatly lowered the yield of 
Table I. Effects of $\mathrm{O}_{2}$ and $\mathrm{H}_{2} \mathrm{O}$ on polymerization of styrene with $\mathrm{Ni} / \mathrm{R}-\mathrm{X}^{\mathrm{a}}$

\begin{tabular}{lccccc}
\hline Halide & $\mathrm{O}_{2}{ }^{\mathrm{b}}$ & $\mathrm{H}_{2} \mathrm{O}^{\mathrm{c}}$ & $\begin{array}{c}\text { Time } \\
\mathrm{hr}\end{array}$ & $\begin{array}{c}\text { Yield, } \\
\%\end{array}$ & {$[\eta]$} \\
\hline \multirow{3}{*}{ tert $-\mathrm{C}_{4} \mathrm{H}_{9} \mathrm{Cl}$} & + & - & 3 & 85.3 & 0.037 \\
& - & - & 3 & 84.0 & 0.022 \\
& + & + & 4 & 2.3 & 0.772 \\
& + & 3 & 0.1 & - \\
\hline & - & - & 3 & 84.0 & 0.023 \\
$\mathrm{CCl}_{4}$ & + & - & 3 & 84.8 & 0.038 \\
& - & + & 3 & 15.8 & 0.134 \\
& + & + & 3 & 7.2 & - \\
\hline None & - & - & 3 & 0.5 & -
\end{tabular}

a Styrene, $5 \mathrm{ml}$; benzene, $5 \mathrm{ml}$; halide, $0.2 \mathrm{ml}$; reduced $\mathrm{Ni}, 0.5 \mathrm{~g}$; temp, $60^{\circ} \mathrm{C}$.

$\mathrm{b}+$ : The polymerization tube was sealed under normal atmospheric conditions.

c +: The reduced nickel was not dried after hydrogenation treatment.

polymer, which was accompanied by an increase in the molecular weight of the polymer. When both inhibitors were present the polymer yield further decreased.

The results obtained above suggested the importance of the cationic mechanism in that polymerization system. The effect of cationic inhibitors was further investigated. Table II gives the results of the polymerization of styrene in the presence of methanol as the cationic inhibitor.

Table II. Effect of methanol on polymerization of styrene with $\mathrm{Ni} / \mathrm{R}-\mathrm{X}^{\mathrm{a}}$

\begin{tabular}{lccrc}
\hline Halide & $\begin{array}{c}\text { Benzene, } \\
\mathrm{m} l\end{array}$ & $\begin{array}{c}\text { Methanol, } \\
\mathrm{m} l\end{array}$ & $\begin{array}{r}\text { Yield, } \\
\%\end{array}$ & {$[\eta]$} \\
\hline $\mathrm{C}_{6} \mathrm{H}_{5} \mathrm{CH}_{2} \mathrm{Cl}$ & 5.0 & 0 & 88.1 & 0.025 \\
& 4.0 & 1.0 & 8.7 & 0.153 \\
tert $-\mathrm{C}_{4} \mathrm{H}_{9} \mathrm{Cl}$ & 5.0 & 0 & 84.0 & 0.023 \\
& 4.0 & 1.0 & 2.7 & 0.695 \\
$\mathrm{CCl}_{4}$ & 5.0 & 0 & 84.7 & 0.023 \\
& 4.5 & 0.5 & 7.7 & 0.085
\end{tabular}

a Styrene, $5 \mathrm{ml}$; halide, $0.2 \mathrm{ml}$; reduced $\mathrm{Ni}, 0.5 \mathrm{~g}$; temp, $60^{\circ} \mathrm{C}$; time $3 \mathrm{hr}$.

In the presence of methanol the yield of polymer was greatly decreased, while the molecular weight of polymer increased. These facts indicate that the polymerization of styrene with
$\mathrm{Ni} / \mathrm{R}-\mathrm{X}$ proceeds predominantly through the cationic intermediate.*

Copolymerization of Styrene and MMA with $\mathrm{Ni}$ Benzyl Chloride

Similar behavior has been observed in the copolymerization of styrene and MMA with $\mathrm{Ni}$ / chlorosilanes. ${ }^{4}$ The monomer-copolymer composition curve deviated from the normal curve of the radical copolymerization indicating high reactivity of styrene, when styrene was present in more than $50 \mathrm{~mol} \%$ in the monomer mixture. This behavior was explained in terms of the overlap of the cationic polymerization of styrene on the radical copolymerization of styrene and MMA. ${ }^{4}$ On the other hand, when carbon tetrachloride was used instead of the chlorosilanes, no abnormality was observed in the monomercopolymer composition curve. ${ }^{3}$

In this study, the copolymerization of styrene and MMA with Ni/R-X was investigated again by using benzyl chloride as the halide component of the initiator. Figure 1 shows the results of the copolymerization.

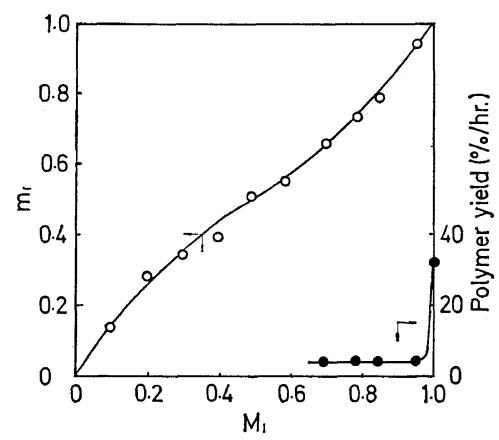

Figure 1. Bulk copolymerization of styrene $\left(M_{1}\right)$ and methyl methacrylate $\left(\mathrm{M}_{2}\right)$ with reduced nickelbenzyl chloride system $\left(60^{\circ} \mathrm{C}\right)$.

In spite of the high cationic activity of $\mathrm{Ni}$ / benzyl chloride, as is shown in Table II, the composition curve obtained corresponded with that of the radical copolymerization. However the yield of polymer was markedly lower in the

* Otsu and Yamaguchi ${ }^{6}$ reported previously that styrene polymerizes with $\mathrm{Ni} / \mathrm{R}-\mathrm{X}$ through the radical mechanism, in contrast to the present result. This difference in the mechanism may be caused by the insufficient drying of the reduced nickel in the previous experiments, inhibiting cationic propagation. 
presence of a small amount of MMA, as compared with the homopolymerization of styrene. This can be resonably explained by the inhibiting effect of MMA for the cationic polymerization of styrene.

These results indicate that the copolymerization method using styrene and MMA, which is widely used as one of the most convenient methods for determining the polymerization mechanism, is not always applicable.

\section{Polymerization of IBVE with $N i / R-X$}

Because IBVE polymerizes only through the cationic mechanism, the polymerization of this monomer with $\mathrm{Ni} / \mathrm{R}-\mathrm{X}$ excludes the radical mechanism. Table III gives the results of the cationic polymerization of IBVE. All halides used were found to be the active component of the initiator. Acetyl chloride and triphenylmethyl chloride showed the highest degree of activity. No polymer was obtained with reduced nickel alone under experimental conditions, though at higher temperatures $\left(>40^{\circ} \mathrm{C}\right)$ polymerization occurred, as reported by Matsumoto and Onishi. ${ }^{7}$

Table III. Polymerization of IBVE with Ni/R-Xa

\begin{tabular}{lccc}
\hline \multicolumn{1}{c}{ Halide } & Time, hr & Yield, $\%$ & {$[\eta]$} \\
\hline $\mathrm{CH}_{2}=\mathrm{CHCH}_{2} \mathrm{Cl}$ & 10 & 12.5 & - \\
$\mathrm{C}_{6} \mathrm{H}_{5} \mathrm{CH}_{2} \mathrm{Cl}$ & 10 & 13.0 & - \\
tert $-\mathrm{C}_{4} \mathrm{H}_{9} \mathrm{Cl}$ & 19 & 16.4 & - \\
$\mathrm{CH}_{3} \mathrm{COCl}$ & very fast & $\sim 100$ & - \\
$\left(\mathrm{C}_{6} \mathrm{H}_{5}\right)_{3} \mathrm{CCl}$ & very fast & $\sim 100$ & 0.394 \\
$\mathrm{CCl}_{4}$ & 10 & 87.3 & 0.240 \\
$\mathrm{C}_{2} \mathrm{H}_{5} \mathrm{Br}$ & 15 & 8.7 & - \\
None & 8 & $\sim 0$ & - \\
\hline
\end{tabular}

a IBVE, $5 \mathrm{~m} l$; benzene, $5 \mathrm{ml}$; halide, $1 \mathrm{mmol}$; reduced $\mathrm{Ni}, 0.5 \mathrm{~g}$; room temp.

It was considered that in the cationic polymerization of IBVE with $\mathrm{Ni} /$ chlorosilanes the reduced nickel behaves like Lewis acid and the halide acts as a cocatalyst. ${ }^{4}$ From this point of view it is difficult to explain the results obtained. In the present work it was observed that carbon tetrachloride has higher activity than tert-butyl chloride (Table III). This contradicts the concept of the cocatalyst in Lewis acidcatalyzed polymerization. Carbon tetrachloride is an inert solvent in the cationic polymerization of styrene catalyzed by stannic chloride, ${ }^{8}$ and tert-butyl chloride is an efficient cocatalyst in that system. ${ }^{9}$

The reaction of the reduced nickel with carbon tetrachloride giving a nickel ion according to eq 1 must be faster than that with tert-butyl chloride and with benzyl chloride on the basis of their dissociation energies of $\mathrm{C}-\mathrm{Cl}$ bonds. ${ }^{1}$. It was considered that nickel chloride produced in situ has an initiating effect in the cationic polymerization, though a commercial anhydrous nickel chloride did not show any activity.

The following experiment was carried out to determine the initiating activity of nickel chloride. Five $\mathrm{m} l$ of carbon tetrachloride was reacted with $0.5 \mathrm{~g}$ of the reduced nickel in a sealed tube at $100^{\circ} \mathrm{C}$ for $4 \mathrm{hr}$. The insoluble materials in the reaction mixture were isolated by decantation, washed with hexane several times, and then dried in vacuo. The solid materials obtained were mixed with $5 \mathrm{ml}$ of IBVE and $5 \mathrm{ml}$ of benzene at room temperature. After $30 \mathrm{~min}$ polyIBVE was obtained at $90.7 \%$ yield indicating the activity of the nickel chloride thus prepared. Presumably a fresh surface of nickel chloride is an important factor in the activity.

\section{Polymerization of IBVE with Nickel Carbonyl/ Carbon Tetrachloride}

It is known that nickel carbonyl/carbon tetrachloride is an effective initiator of the radical polymerization of MMA. ${ }^{10}$ The process of radical formation from this initiator system is the same as that of Ni/R-X. Therefore the nickel chloride which is active for the initiation of the cationic polymerization of IBVE must also be formed.*

Polymerization of IBVE was attempted under the following conditions: IBVE, $8 \mathrm{ml}$; carbon tetrachloride, $0.5 \mathrm{ml}$; nickel carbonyl, $1.6 \mathrm{mmol}$; benzene, $2 \mathrm{ml}$. IBVE polymerized explosively at $60^{\circ} \mathrm{C}$ within $5 \mathrm{~min}$ after immersing the polymerization tube into a thermostat. ${ }^{* *}$ This fact leads to the conclusion that nickel carbonyl/ carbon tetrachloride is both the radical and the cationic initiator.

* The formation of nickel ion was proved by qualitative analysis.

** Nickel carbonyl decomposes into reactive metallic nickel and carbon monoxide above $50^{\circ} \mathrm{C} . .^{11}$ 
Polymerization of Styrene and IBVE with Nickel Oxides $/ R-X$

The cationic polymerization of styrene and IBVE with nickel chloride, which was prepared by the reaction of nickel oxides with alkyl chlorides, was investigated. The reaction of nickel monoxide with carbon tetrachloride is known as a way to prepare nickel chloride. ${ }^{12}$ The formation of nickel chloride in the reaction between nickel sesquioxide and tert-butyl chloride was proved, as will be described in the experimetal section.

The results of polymerization of styrene and IBVE are given in Tables IV and V. Nickel sesquioxide/tert-butyl chloride showed high activity. A commercial anhydrous nickel chloride was found to be inactive.

Table IV. Polymerization of styrene with nickel oxides/R-X $\mathrm{X}^{\mathrm{a}}$

\begin{tabular}{cccc}
\hline Nickel oxide & $\mathrm{R}-\mathrm{X}$ & Time, hr & Yield, \% \\
\hline $\mathrm{NiO}$ & tert $-\mathrm{C}_{4} \mathrm{H}_{9} \mathrm{Cl}$ & 10 & 12.6 \\
& $\mathrm{CCl}_{4}$ & 10 & 0.4 \\
$\mathrm{Ni}_{2} \mathrm{O}_{3}$ & tert $-\mathrm{C}_{4} \mathrm{H}_{9} \mathrm{Cl}$ & 10 & 34.6 \\
& $\mathrm{CCl}_{4}$ & 10 & Trace \\
\multirow{2}{*}{$\mathrm{NiCl}_{2}$} & tert $-\mathrm{C}_{4} \mathrm{H}_{9} \mathrm{Cl}$ & 10 & 0 \\
& $\mathrm{CCl}_{4}$ & 10 & 0.5 \\
\hline
\end{tabular}

a Styrene, $5 \mathrm{ml}$; benzene, $5 \mathrm{ml}$; nickel compd, $0.5 \mathrm{~g}$; halide, $0.2 \mathrm{ml}$; temp, $60^{\circ} \mathrm{C}$.

Table V. Polymerization of IBVE with nickel oxides/R-X $\mathrm{X}^{\mathrm{a}}$

\begin{tabular}{cccc}
\hline Nickel oxide & $\mathrm{R}-\mathrm{X}$ & Time, hr & Yield, \% \\
\hline \multirow{2}{*}{$\mathrm{NiO}$} & tert $-\mathrm{C}_{4} \mathrm{H}_{9} \mathrm{Cl}$ & 14 & Trace \\
& $\mathrm{C}_{6} \mathrm{H}_{5} \mathrm{CH}_{2} \mathrm{Cl}$ & 36 & 0 \\
& $\mathrm{CCl}_{4}$ & 12 & 0 \\
& $\mathrm{CH}_{3} \mathrm{COCl}$ & 14 & 10.5 \\
$\mathrm{Ni}_{2} \mathrm{O}_{3}$ & tert $-\mathrm{C}_{4} \mathrm{H}_{9} \mathrm{Cl}$ & 4 & $83.5^{\mathrm{b}}$ \\
& $\mathrm{C}_{6} \mathrm{H}_{5} \mathrm{CH}_{2} \mathrm{Cl}$ & 36 & Trace \\
& $\mathrm{CCl}_{4}$ & 12 & 0 \\
& $\mathrm{CH}_{3} \mathrm{COCl}$ & 4 & 62.7 \\
\hline
\end{tabular}

a IBVE, $5 \mathrm{ml}$; benzene, $5 \mathrm{~m} l$; nickel compd, $0.5 \mathrm{~g}$; halide, $1 \mathrm{mmol}$; temp, $60^{\circ} \mathrm{C}$.

$\mathrm{b}[\eta]=0.654$.

\section{Friedel-Crafts Reaction}

The fact that the reduced nickel initiates cationic polymerization in the presence of alkyl halides suggested that the reduced nickel may act as a catalyst in the Friedel-Crafts reaction. This was also supported by a study on the effects of solvent in the reaction of the reduced nickel with alkyl chloride producing nickel chloride. ${ }^{13}$ In benzene, tert-butyl chloride and benzyl chloride gave larger quantities of nickel ions than carbon tetrachloride. In dimethylformamide, dimethyl sulfoxide or acetonitrile, however, carbon tetrachloride gave more nickel ions than tert-butyl chloride and benzyl chloride. This difference was explained by a side reaction, i.e., a Friedel-Crafts reaction between benzene and tert-butyl chloride or benzyl chloride catalyzed by nickel chloride produced according to eq 1 , followed by the formation of hydrogen chloride which reacts further with the reduced nickel to produce nickel chloride.

The reaction between tert-butyl chloride and benzene in the presence of the reduced nickel at $60-70^{\circ} \mathrm{C}$ gave tert-butylbenzene and $p$-ditert-butylbenzene. The condensation of benzyl chloride occurred on heating at $70^{\circ} \mathrm{C}$ in the presence of the reduced nickel, and polybenzyl was obtained at high yield. Ir spectrum of the ethanol-insoluble fraction of this polymer (Figure 2) was found to be almost the same as that of the polybenzyl prepared by Haas, et al., by employing benzyl chloride and iron oxide, and it was assumed that the polybenzyl contains the following structure formed by the repeated Friedel-Crafts reaction, as reported by Haas, et al. ${ }^{14}$

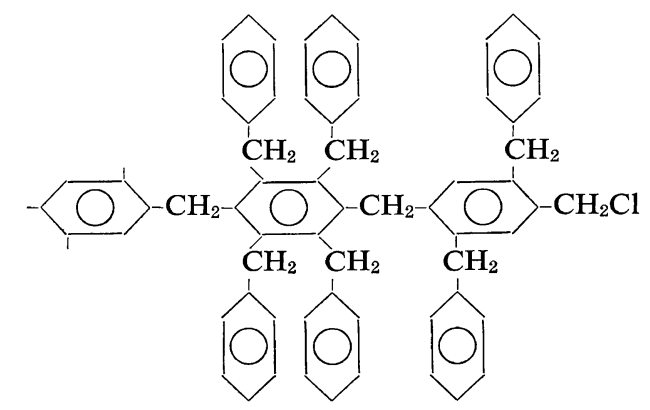

Nickel carbonyl when it was used in the place of the reduced nickel, produced a similar result.

\section{Conclusion}

For the results obtained it was concluded that in the presence of alkyl halides the reduced nickel acts as both a radical and a cationic 


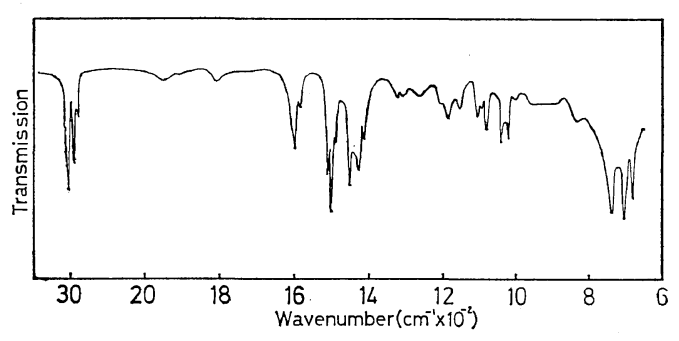

Figure 2. IR spectrum of polybenzyl.

initiator. The nickel chloride produced according to eq 1 acted as the cationic or FriedelCrafts catalyst, though commercial anhydrous nickel chloride did not show any cationic activity. This may be related to the fact that commercial anhydrous nickel chloride becomes active by trituration in the cationic polymerization of styrene and isobutene, ${ }^{15}$ i.e., a fresh surface of nickel chloride is an important factor in the activity.

Another possible mechanism for the cationic initiation which was proposed previously ${ }^{4,5,13}$ is an ionic dissociation of alkyl halides, which is favored in the presence of metals or metallic compounds, followed by addition of the alkyl cation to the vinyl monomer. The initiator system containing acetyl chloride or triphenylmethyl chloride showing high cationic activity, might initiate polymerization through this ionic dissociation mechanism, because these chlorides could easily undergo ionic disociation as well as homolytic dissociation according to eq $1 .^{*}$ The possibility that this mechanism exists cannot be ignored completely. However, at least the cationic initiation with the system containing carbon tetrachloride, which is difficult to dissociate into trichloromethyl cations and chloride anions, excludes this dissociation mechanism.

\section{EXPERIMENTAL}

\section{Materials}

Monomers, solvents, and alkyl halides were carefully purified, with special care taken to remove water. All were redistilled prior to use.

* In the reaction with the reduced nickel triphenylmethyl chloride gave ten times more nickel ions than carbon tetrachloride in benzene, and fifty times more in dimethylformamide. ${ }^{17}$
The reduced nickel composed of 50-\% nickel in kieselguhl (Nikki Chemical Co.) was treated with hydrogen at an high temperature as previously described, ${ }^{3}$ and then dried by evacuation. Nickel carbonyl kindly supplied by Dr. M. Ryang of Osaka University was distilled in a stream of carbon monoxide. Other nickel compounds obtained commercially were used without further purification.

\section{Polymerization}

The polymerization was carried out in nitrogen in a sealed glass ampoule while shaking. After a given period of time the contents of the ampoule were poured into a large amount of methanol to stop the polymerization and to precipitate the resulting polymer. The precipitated polymer was again dissolved in benzene, and the solution was filtered to remove undissolved metals and metallic compounds. The polymer solution was concentrated by evaporation, and then the polymer was reprecipitated by methanol.

The intrinsic viscosity, $[\eta]$, of the polymer was determined in benzene at $30^{\circ} \mathrm{C}$.

\section{Reaction of Nickel Sesquioxide with tert-Butyl Chloride}

A mixture of $1 \mathrm{~g}$ of nickel sesquioxide and $5 \mathrm{~m} l$ of tert-butyl chloride in a sealed tube was heated at $100^{\circ} \mathrm{C}$ for $5 \mathrm{hr}$. After cooling the solid fraction of the mixture was isolated by filtration, washed with hexane, and then extracted with water. Quantitative analysis with dimethylglyoxime showed the presence of $0.27 \mathrm{~g}$ of nickel ion in the water-extractant.

\section{Reaction of tert-Butyl Chloride with Benzere}

Twenty $\mathrm{m} l$ of tert-butyl chloride was reacted with $50 \mathrm{~m} l$ of benzene in the presence of $5 \mathrm{~g}$ of the reduced nickel while stirring in nitrogen at $60-70^{\circ} \mathrm{C}$. The evolution of hydrogen chloride was observed for about $6 \mathrm{hr}$. After cooling the reaction mixture was filtered, and the solid residue was washed with benzene. The distillation of the mixture of the filtrate and the washings gave $1 \mathrm{~g}$ of liquid product which boils at $70-72^{\circ} \mathrm{C}$ $(23 \mathrm{~mm})$. Gas-chromatographic analysis of this product showed it to be tert-butylbenzene containing about $20 \%$ of impurities, in comparison with the authentic sample. The high-boiling point residue in the distillation flask was recry- 
stallized from ethanol, and $2.1 \mathrm{~g}$ of $p$-di-tertbutylbenzene was obtained as a colorless crystalline solid, $\mathrm{mp} 76-77^{\circ} \mathrm{C}$ (lit. $.^{16} 75.5-76.5^{\circ} \mathrm{C}$ ).

Anal. Cacld for $\mathrm{C}_{14} \mathrm{H}_{22}$ : C, 88.35; H, 11.65. Found: C, 88.48; 12.06 .

\section{Condensation of Benzyl Chloride}

Fifty $\mathrm{m} l$ of benzyl chloride was heated in the presence of $5 \mathrm{~g}$ of the reduced nickel while stirring in a nitrogen atmosphere at $70^{\circ} \mathrm{C}$ for 21 hr. The reaction products were fractionated into benzene-soluble and insoluble fractions. The benzene-soluble fraction was further fractionated into ethanol-soluble and insoluble fractions. The results were as follows

\begin{tabular}{lrll} 
Fraction & Weight, g & \multicolumn{1}{c}{ Analysis* } \\
Benzene-insoluble & 26.5 & - \\
Ethanol-insoluble & 11.5 & C, $92.01 ; \mathrm{H}, 6.62 ;$ \\
& & Cl, 1.19 \\
Ethanol-soluble & 1.3 & C, 87.23; H, 6.48; \\
& & Cl, 5.57
\end{tabular}

\section{REFERENCES}

1. T. Otsu, M. Yamaguchi, Y. Takemura, Y. Kusuki, and S. Aoki, J. Polym. Sci., Part B, 5, 697 (1967).

2. T, Otsu, S. Aoki, M. Nishimura, M. Yamaguchi, and Y. Kusuki, J. Polym. Sci., Part B, 5, 835 (1967).

* Calcd for $\mathrm{C}_{7} \mathrm{H}_{6}$ : C, 93.29; H, 6.71.
3. T. Otsu and M. Yamaguchi, J. Polym. Sci., Part A-1, 6, 3075 (1968).

4. T. Otsu, S. Aoki, M. Nishimura, M. Yamaguchi, and Y. Kusuki, J. Polym. Sci., Part A-1, 7, 3269 (1969).

5. S. Aoki, C. Shirafuji, Y. Kusuki, and T. Otsu, Makromol. Chem., 126, 8 (1969).

6. T. Otsu and M. Yamaguchi, Bull. Chem. Soc. Japan, 41, 2931 (1968).

7. T. Matsumoto and A. Onishi, Kogyo Kagaku Zasshi J. Chem. Soc. Japan, Ind. Chem. Sect., 71, 1709 (1968).

8. R. O. Colclough and F.S. Dainton, Trans. Faraday Soc., 54, 886 (1958).

9. R. O. Colclough and F.S. Dainton, Trans. Faraday Soc., 54, 898 (1958).

10. C. H. Bamford and C. A. Finch, Trans. Faraday Soc., 59, 548 (1963).

11. W. L. Gilliand and A. A. Blanchard, Inorg. Syn., 2, 234 (1946).

12. "Encyclopaedia Chimica", Vol. 1, Kyoritsu Shuppan, Tokyo, 1960, p 1058.

13. S. Aoki, A. Akimoto, C. Shirafuji, and T. Otsu, J. Polym. Sci., Part A-1, 8, 785 (1970).

14. H. C. Haas, D. I. Livingston, and M. Saunders, J. Polym. Sci., 15, 503 (1955).

15. K. S. B. Addecott, L. Mayor, and C. N. Turton, Eur. Polym. J., 3, 601 (1967).

16. S. Katsuno, "Synthetic Methods of Organic Compds.," Vol. 4., Gihodo, Tokyo, 1955, p 49.

17. S. Aoki, Y. Iguchi, and T. Otsu, unpublished results. 